\title{
SKOL: DESENVOLVIMENTO E ASCENSÃO DE UMA MARCA 'REDONDA’1
}

\author{
Larissa Crepaldi Trindade, Aline Fernanda Martins de Souza
}

Universidade do Oeste Paulista - UNOESTE. Pós-graduação em Gestão em Marketing e Comunicação, Presidente Prudente-SP. E-mail: linne.martins@hotmail.com

\section{RESUMO}

Diante de um mercado competitivo e inovador, as marcas cada vez mais precisam conquistar seu público-alvo, de forma a estimular a lealdade e preferência. Muitas são as formas de estabelecer esse vínculo, e quanto mais concorrentes a marca possui, mais dificuldade ela tem em se destacar. Muito é dito sobre os elementos que compõem uma comunicação eficiente. Na história de uma marca, cada decisão deve ser bem pensada e bem implantada para que os resultados correspondam às expectativas. Contudo, a trajetória de sucesso deve ser considerada a partir do início, quando há apenas planejamento e nada concreto. Todos os aspectos devem concorrer a um mesmo objetivo, fato que torna essencial a definição de um arquétipo para construção da marca.

Palavras-chave: Estudo de caso. Posicionamento. Marca. Arquétipo. Skol.

\section{SKOL: DEVELOPMENT AND RISE OF A 'ROUND' BRAND}

\begin{abstract}
Face of a competitive and innovate market, brands need to gain the target public, in order to get the loyalty and the preference. There are many ways to get this link, and the more competitors the brand has, more are the difficulties it needs to be pointed out. Much is said about the elements that are in an effective communication. In the brand's history, every decision should be well thought and well done so the results correspond to the expectations. However, the success trajectory must be considered from the beginning, when there are only planning and nothing concret. All the aspects must compete to the same goal, fact thats make essencial to define a archetype to build the brand.
\end{abstract}

Keywords: Case study. Positioning. Brand. Archetype. Skol

${ }^{1}$ Trabalho apresentado para a disciplina de Gestão de Marcas, da Especialização Gestão em Marketing e Comunicação da Pós-Unoeste (SP). 
INTRODUÇÃO

“As empresas da pós-modernidade são grandes laboratórios e estão sempre em total processo de mudança" (FERREIRA, 2014).

Adotando um posicionamento que defende a descontração, a socialização e a inovação, a Skol conseguiu com suas ações, a empatia do consumidor.

Hoje as marcas fazem parte do dia a dia e seus atributos influenciam o processo de decisão de todos os públicos estratégicos [...]. Em muitos casos, as marcas facilitam o processo de decisão dessas pessoas e acabam, na verdade, gerando padrões de referência de qualidade no cotidiano. (TOMIYA, 2010, p. 24).

Com o intuito de analisar a gestão de marca da Skol, esse trabalho foi desenvolvido considerando sua trajetória de sucesso no país, com base em um vídeo da campanha "Churrasco Redondo é Rir da Vida".

\section{METODOLOGIA}

A pesquisa foi produzida segundo o método de estudo de caso que, considera vários aspectos do fenômeno estudado, segundo Godoy (1995, p. 25). A autora ainda afirma que dessa forma, "o pesquisador geralmente utiliza uma variedade de dados coletados em diferentes momentos, por meio de variadas fontes de informação".

Seguindo esta linha, a coleta de dados foi realizada por distintos meios, levando em conta a vasta gama de informações relacionadas à empresa, portanto, foram consultados desde conteúdos institucionais a documentos científicos oriundos de outras pesquisas.

\section{HISTÓRICO DA MARCA}

De origem dinamarquesa, a Skol foi fundada em 1964, proveniente da junção das cervejarias Allied Breweries, Labatt, Pripps-bryggerierna e Unibra, do Reino Unido, Canadá, Suécia, e Bélgica, respectivamente, que possuíam o objetivo de criar uma marca de alcance internacional, segundo o site Mundo das Marcas (2006).

O nome "Skol" surgiu com base na língua sueca, cujo significado é "à sua/ nossa saúde", expressão tradicionalmente dita antes de um brinde.

No Brasil, a marca chegou em 1967, através da Cervejaria Rio Claro, fabricante da Caracu. Em seguida, a Brahma tornou-se a responsável, passando para a Companhia de Bebidas das Américas (Ambev), apenas em 1999, quando tomou a liderança no mercado brasileiro e o quarto lugar no mundo de cerveja mais vendida, segundo o site da companhia (AMBEV, 2014). 
A Skol representa a inovação de produtos cervejeiros, já que toda sua história é marcada por lançamentos audaciosos. Segundo o site Mundo das Marcas (2006), a empresa iniciou seu grande movimento de marketing, com os investimentos realizados durante a década de 90, quando estabeleceu sua participação em eventos voltados aos jovens e deu o primeiro passo para o posicionamento que mantém hoje, com a criação do slogan: "a cerveja que desce redondo".

\section{ARQUÉTIPO DA MARCA}

A forma com a qual o consumidor enxerga a marca, ou decide pela compra ou não de seus produtos, sofre diversas influências, tanto externas quanto internas.

Para Kotler (1995 apud CARDOZO, 2004, p. 69), o comportamento do consumidor pode ser influenciado por fatores culturais, sociais, pessoais e psicológicos.

$\mathrm{O}$ arquétipo da marca atinge o nível psicológico do consumidor, uma vez que utiliza de seus próprios desejos para influenciá-lo na escolha do produto, "por representarem um modelo de vida ideal, que os sujeitos interpretantes - no caso, os destinatários da mensagem publicitária - almejam [...]." (BICALHO; BERG, p. 4).

As ações da marca Skol baseiam-se essencialmente no arquétipo Bobo da Corte, que representa a diversão, com a oferta de alegria e descontração. Esses traços são vistos em todas as suas campanhas, em contextos e situações cotidianas.

No vídeo "Churrasco - Redondo é Rir da Vida", é possível identificar já a partir do nome do título, a leveza com a qual a marca trata do assunto, e mais do que isso, o tema escolhido já é o bastante para evidenciar o enfoque da campanha: socialização.

No churrasco são compartilhados risos e brincadeiras, que levam ao consumidor a sensação de leveza e prazer, já que o encontro entre amigos ocorre num ambiente descontraído onde são evidenciados os bons momentos. A cerveja torna-se parte de um todo, ou seja, tudo que é bom pode ser ainda melhor com a Skol.

\section{POSICIONAMENTO}

Segundo Aaker (1998, apud TOMIYA, 2010, p. 60), "o posicionamento de marca deve partir da identidade da marca. Sua proposta tem de ser diferenciada, única e comunicada para o públicoalvo, deixando muito claras as vantagens em relação aos principais concorrentes."

Considerando que o posicionamento nada mais é do que a imagem transmitida pela marca e vista pelo consumidor, a Skol se posiciona de forma leve, despojada, divertida e jovial, com 
campanhas que despertam bem estar e alegria, de forma que introduz o consumidor em um mundo desejado, que é o de satisfação, diversão, sem a existência de problemas.

[...] Podemos depreender que o simulacro construído para a marca em questão corresponde à tentativa de socialização. O consumidor, sempre apresentado como o "fanfarrão", busca recorrentemente enturmar-se, pertencer ao grupo e socializar. Ao contrário de marcas como a Bohemia, que constrói um percurso narrativo para o simulacro de seu consumidor relacionado a valores como a nobreza, a estesia do produto, e as propriedades artísticas de sua fabricação, a Skol ocupa uma posição diametralmente oposta. (SCOZ, 2009, p. 8).

Diante do slogan da campanha-objeto da análise, Redondo é Rir da Vida, fica claro que a Skol não busca evidenciar a própria cerveja. Ela se aproxima do consumidor através do clima de descontração, amizade e diversão, e a sensação de bem estar causada, é a responsável pela empatia entre consumidor e marca.

Este é o diferencial entre a Skol e outras marcas: ela faz parte do programa entre amigos, das reuniões e encontros, como parte de um todo, estabelecendo o clima divertido e de jovialidade.

\section{ELEMENTOS DE BRANDING DA MARCA}

Para Aaker (1998, p. 16), “o brand equity é um conjunto de ativos e passivos ligados a uma marca, seu nome e seu símbolo, que se somam ou se subtraem do valor proporcionado por um produto ou serviço".

O autor ainda apresenta os elementos que estruturam este conjunto, aplicados em contextos específicos, e classificados como: lealdade à marca; conhecimento do nome; qualidade percebida; associações à marca em acréscimo à qualidade percebida, e outros ativos como patentes, por exemplo.

A Skol não possui extensões de linha, trabalha exclusivamente com a cerveja, que possui apenas variações em seus tipos de embalagem ou na fórmula. Dessa maneira, fomenta a aceitação da marca por parte dos consumidores, já que mantém seu conhecimento e a boa qualidade do produto, investindo sempre em inovação e tecnologia.

Segundo alguns autores a evolução da marca passa por três estágios: assertivo, assimilativo e absorvitivo. No primeiro estágio, [...] a marca fala para o consumidor, comunica seu ponto de vista, dizendo que são as melhores e que basta confiar nelas para se fazer a coisa certa. No segundo estágio, [...] as marcas assumem uma posição de diálogo, em que o cliente pensa que pode ser importante para o crescimento da marca (é uma relação de igualdade e participação). No terceiro estágio, [...] as marcas assumem uma posição de convívio, tornam parte da vida do consumidor, motivando-o não só a utilizar sua 
marca, mas tudo o que se relaciona a ela. E isso é o que define o branding, a fidelidade do cliente pela marca." (O MELHOR DO MARKETING, 2009)

\section{PRODUTOS}

Os variados tipos de embalagem fazem com que a marca se aproxime do consumidor, por oferecer mais facilidade e claro, ir de encontro à necessidade do cliente: a cerveja litrão que rende mais nos churrascos; a big neck que conserva o sabor encontrado na embalagem de vidro, porém em tamanho menor; e a redondinha, que gela mais rápido.

Com o intuito de se aproximar ainda mais do seu público-alvo, que se trata de jovens de 18 a 27 anos, a marca promoveu eventos ligados a musica, e ainda investe neste tipo de intervenção, sendo que os mais conhecidos são:

SKOL BEATS, festival que abrangia os mais diversos estilos de música eletrônica, sendo a primeira marca a investir neste tipo de evento no ano de 2000 , quando foi realizada a primeira edição; [...] SKOL FOLIA, projeto no qual a marca busca estar presente nos principais eventos de música baiana do país; SKOL SENSATION, um espetáculo de sensações com os melhores DJs, performances, sons e luzes, realizado pela primeira vez em 2009 e que se transformou no maior evento de música eletrônica do planeta, [...] SKOL RADIO, um novo aplicativo para internet, [...], que permite acompanhar as últimas tendências do cenário pop, conferir agendas de eventos e personalizar playlists. (Mundo das Marcas, 2006)

Os produtos atualmente disponíveis no mercado variam de acordo com as regiões brasileiras. No endereço eletrônico da empresa, as variações da cerveja Skol são as discriminadas a seguir: Latas de 269 ml, $350 \mathrm{ml}$ e $550 \mathrm{ml}$, Big Neck, Beats Extreme, Garrafa ( $250 \mathrm{ml}$ e $300 \mathrm{ml}$ ), Skol $360 \cong(350 \mathrm{ml})$, Beats $330 \mathrm{ml}$, Latão $(473 \mathrm{ml})$ Tradicional e 360ㅇ, Garrafa (600 ml) Tradicional e $360^{\circ}$, Long Neck, e Litrão (600 ml e 360ํ). (SKOL, 2014)

\section{SIMBOLOGIA}

Nome, símbolo e slogan possuem peso importantíssimo para o sucesso de uma marca, portanto, é necessário que haja relação entre eles, de modo que um elemento case com o outro, estabelecendo uma constante lembrança entre produto e empresa.

A Skol, como já foi dito, teve seu nome inspirado em uma expressão dita durante o brinde, relacionada com o que sua marca propõe: a socialização, no entanto, por seu slogan se remeter à "cerveja que desce redondo", por conta de ser uma bebida mais leve, estabeleceu-se essa relação aplicando no símbolo, a seta que indica movimento rotatório. 
“Descer redondo é a forma como a F/Nazca (em 1996) descreveu as características sensuais da Skol, um sabor mais suave e menos amargo que das concorrentes." (MUNDO DAS MARCAS, 2006)

O símbolo pode também ajudar o nome da marca a se associar, a uma classe de produto, estabelecendo com esta uma ligação. A pesquisa sobre a psicologia e o comportamento do consumidor, proporciona pistas sobre a espécie de características do símbolo, que afetará a sua capacidade de se ligar com a marca e a classe de produto. (AAKER, 2010, p. 212).

Desde a década de 90, a seta que remete ao "redondo" foi aplicada na letra O do nome da marca.

\section{COMUNICAÇÃO}

Por se tratar de uma marca que busca atingir o público estabelecendo a ideia de juventude e diversão, a Skol faz uso das mídias tradicionais e online. Nos anúncios de TV, Jornal e Revista busca traduzir em pouco tempo e espaço, a mensagem que prega: descontração.

Seguindo a tendência mundial, que também é vista no Brasil, a Skol viu a necessidade de estar presente nas mídias sociais. Utilizando os meios digitais, possui outras formas, mas não menos eficientes de atingir seu público: com campanhas divertidas e inovadoras, envolve o consumidor em seu mundo leve e alegre, propõe a participação em promoções, e desenvolve ainda mais a ideia de marca jovem.

Em relação à presença da marca em acesso a rede por telefones móveis, a inovação é percebida em dois aplicativos: Rádio Skol e GPS Skol. Os consumidores da cerveja podem baixar em seus celulares a Rádio Skol, que durante 24 horas por dia oferece programação musical. Já o GPS Skol, orienta os usuários sobre os locais mais próximos de onde estão, destinados ao consumo da cerveja.

A Skol está presente no Instagram, Facebook e Twitter. Dessa forma, estreita os laços entre consumidor e marca, interagindo, informando e estabelecendo a comunicação nos principais meios utilizados pelos internautas.

\section{CONSIDERAÇÕES FINAIS}

Uma marca deve fazer sentido tanto para si, com sua missão, visão e valores, quanto para o consumidor, que deve consumir seu produto para mantê-la no mercado, mas nessa cadeia de ações, muitos elementos constroem ou destroem essa relação. 
A Skol, em toda sua trajetória no Brasil, demonstra um constante trabalho de gestão de marca e comunicação dirigida. Como tomou um posicionamento que aponta para a socialização entre as pessoas, e veste um arquétipo direcionado para a diversão e prazer, atinge o mercado com campanhas descontraídas.

O churrasco divertido com o amigo que leva cerveja quadrada e toma a Skol redonda, que incomoda os vizinhos e diverte os colegas: esse é o contexto onde a marca demonstra o lado bom da vida, e como ele pode ser ainda melhor se a Skol fizer parte.

\section{REFERÊNCIAS}

AAKER. David A. Marcas: Brand Equity: Gerenciando o Valor da Marca. São Paulo: Elsevier, 1998.

AMBEV. Companhia de Bebidas das Américas. 2014. Disponível em: <http://www.ambev.com.br/nossas-marcas/cervejas/skol-pilsen>. Acesso em: 18 de janeiro de 2014.

BICALHO. V; BERG. M. A Representação Semiótica dos Arquétipos: Como o Discurso Publicitário Representa os sujeitos Consumidores a partir da Projeção Identitária. Apresentado na Universidade Federal de São João Del Rey. Disponível em <http://www.filologia.org.br/ixfelin/trabalhos/pdf/08.pdf>. Acesso em: 16 de janeiro de 2014.

Campanha Publicitária SKOL - Churrasco "Redondo é Rir da Vida. Disponível em: <http://www.youtube.com/watch?v=w_NT2fPI_rU>. Acesso em: 16 de janeiro de 2014.

CARDOZO, M. A construção emocional das marcas: o uso de arquétipos e estereótipos. Disponível em <http://seer.uscs.edu.br/index.php/revista_comunicacao_inovacao/article/view/601/444. Acesso em: 18 de janeiro de 2014.

GODOY. A. Schmidt. Pesquisa Qualitativa - Tipos Fundamentais. Disponível em http://www.producao.ufrgs.br/arquivos/disciplinas/392_pesquisa_qualitativa_godoy2.pdf. Acesso em: 4 de setembro de 2014

Mundo das Marcas. História da Skol. Disponível em: <http://mundodasmarcas.blogspot.com.br/2006/05/skol-cerveja-que-desce-redondo.html>. Acesso em: 16 de janeiro de 2014.

O Arquétipo - Um pouco de marketing e muitas histórias. Case Skol. Disponível em: <http://oarquetipo.wordpress.com/caso-skol/>. Acesso em: 24 de maio de 2014.

O Melhor do Marketing. Posicionamento de Marca. Disponível em: <http://www.omelhordomarketing.com.br/posicionamento-de-marca/>. Acesso em: 24 de maio de 2014.

Propaganda e Design. A gestão de marca na pós-modernidade. Disponível em: http://matheusferreira.com.br/academico-a-gestao-de-marca-na-pos-modernidade/ Acesso em: 12 de junho de 2014. 
ROSA, E. A construção de relacionamentos emocionais entre marca e consumidor: Um estudo de caso da Skol. 2011. 105 f. Graduação em Comunicação Social na Faculdade de Comunicação Social, da Universidade Federal de Juiz de Fora. Disponível em:

<http://www.ufjf.br/facom/files/2013/04/EduardodeSouzaSimonettedaRosa.pdf>. Acesso em: 24 de maio de 2014.

SCOZ, M. Estatuto Semiótico de Marcas Brasileiras de Cerveja: O Bebedor Fanfarrão da Skol. Anais do II Seminário: Leitura de Imagem para a Educação: múltiplas mídias. Florianópolis, 2009. Universidade do Estado de Santa Catarina/ UDESC. Disponível em <http://www.gpae.ceart.udesc.br/artigos3/artigo-MuriloScoz.pdf>. Acesso em: 16 de janeiro de 2014.

TOMIYA. Eduardo. Gestão do Valor da Marca: Como criar e gerenciar marcas valiosas. Rio de Janeiro: Senac, 2010 